
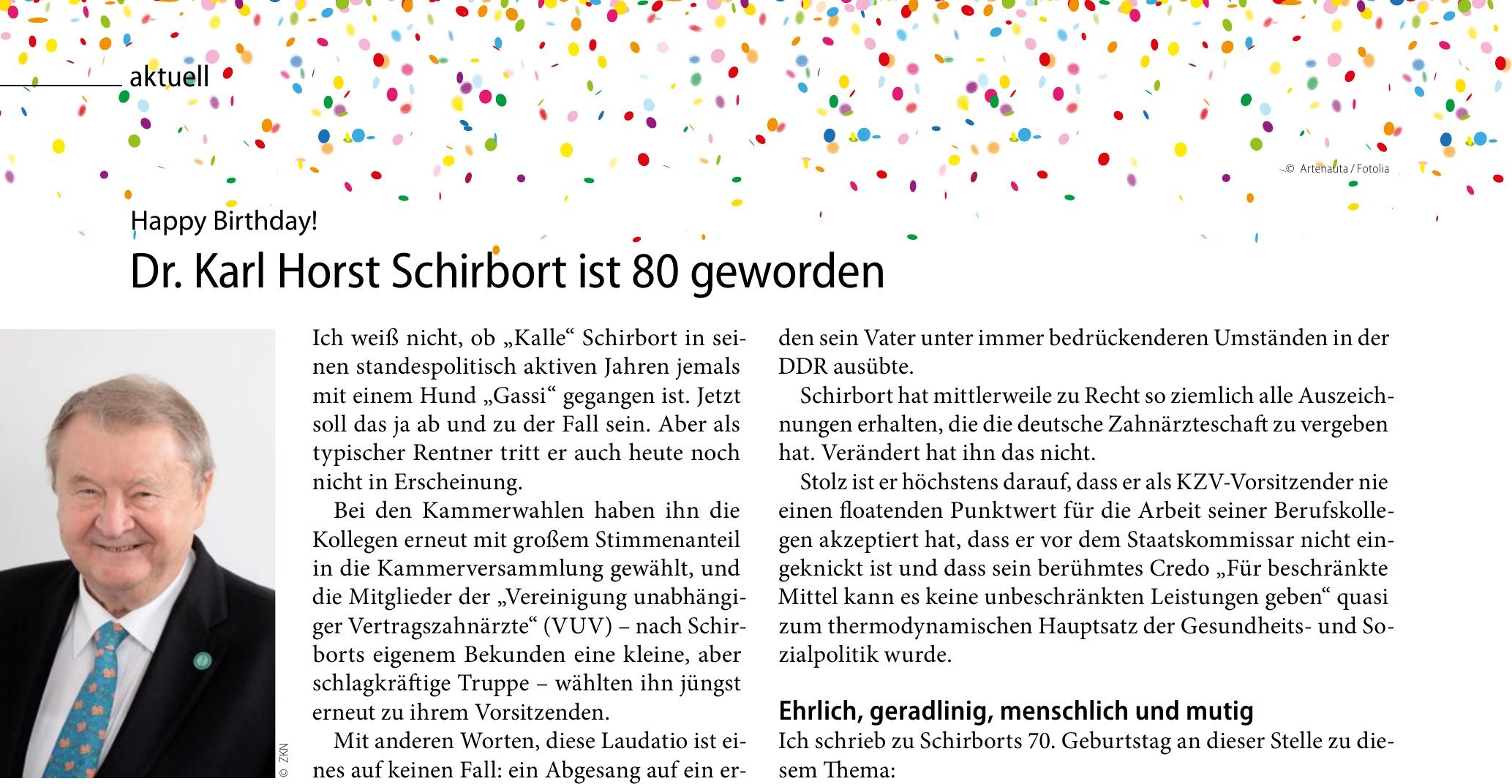

Happy Birthday!

Dr. Karl Horst Schirbort ist 80 geworden

Ich weiß nicht, ob „Kalle“ Schirbort in seinen standespolitisch aktiven Jahren jemals mit einem Hund „Gassi“ gegangen ist. Jetzt soll das ja ab und zu der Fall sein. Aber als typischer Rentner tritt er auch heute noch nicht in Erscheinung.

Bei den Kammerwahlen haben ihn die Kollegen erneut mit großem Stimmenanteil in die Kammerversammlung gewählt, und die Mitglieder der „Vereinigung unabhängiger Vertragszahnärzte“ (VUV) - nach Schirborts eigenem Bekunden eine kleine, aber schlagkräftige Truppe - wählten ihn jüngst erneut zu ihrem Vorsitzenden.

Mit anderen Worten, diese Laudatio ist eines auf keinen Fall: ein Abgesang auf ein ereignisreiches standespolitisches Leben. Im Gegenteil: Dr. Karl Horst Schirbort bleibt der Seher, der Warner, er bleibt der Kritiker einer Gesundheitspolitik, die eindeutig in Richtung Staatsmedizin orientiert ist und scheibchenweise die Rechte der Freiberuflichkeit einschränkt und abbaut. Der fürsorgende Sozialstaat, dem die Freiberuflichkeit - trotz aller Lippenbekenntnisse - suspekt ist, das ist Schirborts Gegner.

\section{Zu Recht sehr oft ausgezeichnet}

Denn es steckt ihm bis heute „in den Knochen“, wie aus freien Zahnärzten unter ideologischer Beeinflussung die sozialistischen Erfüllungsgehilfen eines staatlichen Gesundheitswesens geformt wurden. Diese DDR-Erfahrung prägte sein Leben bereits in jungen Jahren, damals, als er in den Westen fliehen musste, um an einer Freien Universität den Beruf zu studieren, den sein Vater unter immer bedrückenderen Umständen in der DDR ausübte.

Schirbort hat mittlerweile zu Recht so ziemlich alle Auszeichnungen erhalten, die die deutsche Zahnärzteschaft zu vergeben hat. Verändert hat ihn das nicht.

Stolz ist er höchstens darauf, dass er als KZV-Vorsitzender nie einen floatenden Punktwert für die Arbeit seiner Berufskollegen akzeptiert hat, dass er vor dem Staatskommissar nicht eingeknickt ist und dass sein berühmtes Credo „Für beschränkte Mittel kann es keine unbeschränkten Leistungen geben“ quasi zum thermodynamischen Hauptsatz der Gesundheits- und Sozialpolitik wurde.

\section{Ehrlich, geradlinig, menschlich und mutig}

Ich schrieb zu Schirborts 70. Geburtstag an dieser Stelle zu diesem Thema:

„Als Dr. Karl Horst Schirbort Mitte der 90er Jahre als KZBVVorsitzender die Budget-Debatte eröffnete und mit diesem Thema über Wochen bundesweit auf Seite eins aller Medien präsent war, erfuhr die Öffentlichkeit erstmals, was sich hinter dem Begriff „Budget“ verbirgt“. Durch den Satz „Für beschränkte Mittel kann es keine unbeschränkte Leistung geben“ wurde das Seehofersche Wundermittel zur Kostendämpfung von heute auf morgen als Mogelpackung entlarvt.

Auch schrieb ich vor 10 Jahren: „Was uns bis heute beeindruckt, ist seine Vitalität, seine verlässliche Ehrlichkeit und Geradlinigkeit, sein Durchhaltevermögen, seine große Menschlichkeit und sein geradezu unerschütterlicher Mut.“

Besser kann ich es heute auch nicht ausdrücken. Damals als Landesvorsitzender, heute immer noch als Freund und Weggefährte.

Lieber Kalle, bleib gesund und Gott befohlen! Dr. Julius Beischer

\title{
Vertreterversammlung wählt neues Vorstandstrio
}

Die Kassenärztliche Bundesvereinigung (KBV) wird in den nächsten sechs Jahren erstmals von einem Vorstandstrio geführt. Darunter gibt es zwei neue Gesichter: An der Spitze der Körperschaft bestätigte die Vertreterversammlung (VV) bei den Wahlen Anfang März Amtsinhaber Dr. Andreas Gassen. Der Orthopäde übernahm das Amt des Vorstandsvorsitzenden 2014 von Dr. Andreas Köhler, der den Posten aus gesundheitlichen Gründen aufgegeben hatte.

Gassen führte in den vergangenen drei Jahren gemeinsam mit der Allgemeinmedizinerin Regina Feldmann die Geschäfte der Kassenärzte. Feldmann trat nicht mehr für eine weitere Amtsperiode an und machte den Weg für einen Nachfolger aus dem Lager der Hausärzte frei. Mit deutlicher Mehrheit wählte die VV den bisherigen stellvertretenden Vorsitzenden der Kassenärztlichen Vereinigung Hamburg, Dr. Stephan Hofmeister. Als zweiten stellvertretenden Vorsitzenden votierten die VVDelegierten für Dr. Thomas Kriedel, der bis Jahresende 2016
Vorstand der Kassenärzte in Westfalen-Lippe war. Nach der Wahl gab Gassen die Richtung für die neue Amtsperiode vor: „Wir Vertragsärzte und Vertragspsychotherapeuten können offen in die Debatten gehen - jeder weiß, was man inhaltlich von uns zu erwarten hat. Nun kommt es darauf an, dass wir gemeinsam in die Politik hineinwirken und jene Durchschlagskraft zurückgewinnen, die wir wegen vieler Querelen in den vergangenen Jahren eingebüßt haben.“

In den vergangenen Jahren sorgte die KBV vor allem durch Personalunstimmigkeiten und umstrittene Immobiliengeschäfte für Negativschlagzeilen. Das Ende Januar vom Bundestag beschlossene GKV-Selbstverwaltungsstärkungsgesetz ist eine Reaktion auf die Unregelmäßigkeiten und Missstände aus der Vergangenheit. Das Gesetz schreibt für die KBV künftig einen dreiköpfigen Vorstand aus einem Facharztvertreter, einem Vertreter aus dem Lager der Hausärzte und einer dritten Person im Vorstand vor, die nicht Mediziner ist. 